\title{
NASA's Dual-Fuel Airbreathing Hypersonic Vehicle Study
}

\author{
by \\ James L. Hunt* \\ NASA Langley Research Center; Hampton, Virginia
}

and

\author{
Edward A. Eiswirth** \\ McDonnell Douglas Aerospace; St. Louis, Missouri
}

\section{Introduction}

Hypersonic airbreathing, horizontal takeoff and landing (HTOL), vehicles are highly integrated systems involving many advanced technologies. The design environment is variable rich, intricately networked, and sensitivity intensive; as such, it represents a tremendous challenge. Creating a viable design requires addressing three main elements: (1) an understanding of the "figures of merit" and their relationship, (2) the development of sophisticated configuration discipline prediction methods and a synthesis procedure, and (3) the synergistic integration of advanced technologies across the discipline spectrum.

Airbreathing hypersonics encompasses endoatmospheric and space access vehicles with speeds from Mach 4 up to Mach 25 (orbital). This vehicle matrix can be divided into two classes-accelerators and cruisers.

The dominant design characteristic of the accelerator is low drag per unit inlet capture; thus the cross section of the accelerator attributes a large percentage to propulsion. On the other hand, the conventional figure of merit for cruiser designs is high lift-to-drag ratio and thus they lend toward thin/flat fuselages with high fineness ratios.
One of the more design-influencing items shaping the configuration is fuel. The hydrogen-fueled vehicles must be very volumetric efficient to contain the low density fuel, and thus tend to be a bit bulgy; whereas with hydrocarbon-fueled vehicles, the concern is loading because of the high density fuel. Thus, they may tend to be more like waveriders which are not usually very volumetrically efficient. While there is considerable synergy between the two classes of vehicles including aspects of engine integration, systems and configuration shaping, this paper will focus on the airbreathing hypersonic cruise vehicle and its prospects with respect to global reach from a CONUS base.

\section{Figures of Merit}

For endoatmospheric vehicles, range for a given payload at a given cruise Mach number is a good figure of merit. How is this figure of merit impacted for hydrocarbon-fueled airplanes and liquid hydrogen-fueled airplanes? The answer is indicated in Figure 1. The hydrocarbon-fuel cruise Mach limit is about 8 because preliminary calculations indicate that Mach 8 is approximately the cruise speed extent to which a dual-mode ramjet/scramjet can be cooled with endothermic fuels for optimum performance contraction ratios. This result is dependent on contraction ratio and dynamic

* Manager of Systems Analysis Office, Associate Fellow, AIAA

** Engineering Manager, Associate Fellow, AIAA 
pressure and thus a reduction in contraction ratio below about 15 at Mach 8 or dynamic pressure below 750 psf would extend the cooling capability beyond this Mach number. On the other hand, liquid hydrogen has much more cooling capacity and provides considerably more range than hydrocarbons for the same cruise Mach number as indicated in Figure 1.

The cruise speed focus of this paper, Mach 10 , evolved to a major extent from Figure 1. The range for hydrogen-fueled cruise airplanes maximizes at about Mach 10 (beyond the cooling limits of the endothermic hydrocarbons). This is because Mach 10 is about the point of dimensioning returns on acceleration at the higher equivalence ratios relative to cruise at the lower equivalence ratios (higher specific impulse). Other factors that favor the Mach 10 focus are: (1) increasing the cruise Mach number doesn't decrease time-to-target proportionately because such a large fraction of the total mission time is in the acceleration phase and (2) Mach 10 cruise speeds and altitude should be sufficiently high to assure survivability.

The takeoff gross weight (TOGW) of the hydrocarbon-fueled airplanes is much greater for the same cruise Mach number than that for the hydrogen-fueled airplanes as shown in Figure 2. Since the density of the hydrocarbon fuel is much greater than that of hydrogen, the planform loading will be even more exaggerated towards the hydrocarbon-fueled vehicles and thus the magnitude of takeoff speeds and balanced field lengths could become major concerns. The dry weight of hydrocarbon vs. hydrogen airplanes for the same cruise Mach number and for the same payload is a much closer call, it still tends to break favorably for the hydrogenfueled airplanes as indicated in Figure 2.

\section{Performance Potential}

The hypersonic airbreathing vehicles matrix being explored in Langley's Systems Analysis Office (SAO) for both space access and hypersonic cruise, as presented in Figure 3, could serve to provide a conceptual performance gage in terms of global reach potential.

Conceptual performances for endoatmospheric operations that were considered in February 1995 to scope the potential are given in Figure 4 for three vehicles with space access capability-Single-Stage-to-Orbit (SSTO, Ref. 1), 1st stage of Mach 102 2STO launch system and 1st stage of Mach 15 2STO launch system (conceptual designs)-and a Mach 5 waverider, hydrocarbon-fueled aircraft (Ref. 2). The figure indicates that hydrogen and/or slush hydrogen fueled, hypersonic airbreathing launch systems with enclosed payload bays have considerable endoatmospheric capability. The 1st stage of a 2STO that stages at Mach 10 when performing as a cruise airplane could possibly cover a range of nearly $10 \mathrm{~K} \mathrm{~nm}$ (ground-to-ground) with a payload of $10 \mathrm{k}$ lbs. for about $300 \mathrm{~K}$ lbs. of gross weight. Essentially the same vehicle could possibly deliver up to $7 \mathrm{~K}$ lbs. to orbit with a hydrogen-fueled 2 nd stage. It would have to perform a pull-up at Mach 10.

The hydrocarbon-fueled waverider comes up comparatively short. Its ground-to-ground range with $10 \mathrm{~K}$ payload is less than $6,000 \mathrm{~nm}$ for a $550 \mathrm{~K} \mathrm{lb}$. gross weight (Ref. 2), but the loading may be excessive for viable takeoff speeds.

The global coverage potential of hypersonic airplanes with $10 \mathrm{~K} \mathrm{~nm}$ range over-point from Langley and Vandenberg air bases (Figure 5) presents an interesting perspective. Less than $10 \%$ of the earth's surface is not accessible from these two CONUS bases, and this inaccessible area is essentially over the Indian Ocean, where there is nothing to access. With Mach 10 cruise capability, $10 \mathrm{k} \mathrm{nm}$ can be covered in 90 minutes-long range, quick response. 


\section{The Global Reach Scenario}

From the previous discussions, consider the overall synergistic perspective presented in Figure 6. For global reach from a CONUS base, a Mach 10 cruise vehicle and an Air Core Enhanced Turboramjet (AceTR) lowspeed propulsion system with high installed thrust-to-weight that operates on hydrocarbon fuel (endothermic) could have many favorable characteristics-quick response, hydrogen fuel to cool, and provide long range in a reasonably low takeoff gross weight vehicle. The dual-fuel feature of this vehicle would provide a logistically manageable, synergistic system capable of in-air refueling for a return leg below Mach 4. An integrated rocket system at the trailing edge of the vehicle would allow the aircraft to perform a pull-up for staging of an upper stage from an enclosed payload bay to provide orbital access. Use of advanced technologies for multiple purposes makes such a system easier to justify (cost).

Quick response, global coverage from CONUS bases is a vision that emanates from the top echelons of the U.S. government/Air Force. In this regard, officials at NASA Langley's Hypersonic Vehicles Office awarded a contract to McDonnell Douglas Aerospace (MDA) on August 6, 1996 to explore designs for vehicles capable of flying at ten times the speed of sound (Mach 10).

The contract, entitled "Dual-Fuel Airbreathing Hypersonic Vehicle Design Study," was planned for 30 months and had a total value of almost $\$ 3$ million. The first phase of the study, lasting seven months, concentrated on developing designs for a CONUS-based, Mach 10 reconnaissance aircraft (Mission A in Figure 7). The work was performed in St. Louis by MDA's Advanced Systems and TechnologyPhantom Works. Pratt \& Whitney of West Palm Beach, Florida, provided propulsion/propulsion integration support, and the University of Maryland in College Park, Maryland, and Astrox Corporation of Rockville, Maryland provided assistance in assessing high lift-to-drag (L/D) vehicle concepts. The second phase was to examine the possibility of using such a vehicle in a space access role (Mission B in Figure 7). This second phase was postponed to move forward on phase III-a Hyper-X research vehicle design to allow flight testing of an airframe integrated scramjet configuration (based on Phase I configuration results) at Mach 5, 7, and 10. The focus here is the first phase-CONUSbased, Mach 10 global reach airplane design.

\section{Phase I Dual-Fuel Study}

The Dual-Fuel Study (phase I) design space (Ref. 3) is shown in Figure 8 in terms of trades and studies that included configurations, performance, systems, and missions. Three classes of configuration were investigated-lifting body, waverider, and cone body. The liftingbody configuration taken as the point of departure for this study was one which had received a substantial amount of development through several Air Force-funded studies (References 1 and 2). The waverider was developed under subcontract by the University of Maryland (UMD) and the Astrox Corporation (AC) using advanced waverider definition techniques. The cone body was a collaborative effort among UMD, NASA Langley, and MDA.

The selected concept was a lifting-body configuration illustrated in Figure 9. It employs Air-core enhanced TurboRamjet (AceTR) engines for low-speed flight (Mach 0 to 4.5) and slush hydrogen-fueled, dual-mode $\mathrm{ram} / \mathrm{scramjet}$ engines for high-speed flight (Mach 4.5 to 10). The structural architecture is comprised of an integral graphite/epoxy cryogenic hydrogen tank with a mechanically bonded Thermal Protection System. 


\section{Mission Scenarios}

Two candidate operational scenarios are shown in Figure 10. The baseline mission involves takeoff from a CONUS base, climb to cruising altitude and Mach number, completion of a $2.5 \mathrm{~g}$ turn at the target at minimum power, and unpowered, maximum L/D descent following the turn for rendezvous with a tanker, and a multiple-fueled subsonic return to base. The maximum mission radius for the reference vehicle requires several refuelings for the return flight. The turbine engine is used during takeoff and the initial climb up to Mach 4.5, and also for the tanker rendezvous, return flight, and landing. The ram/scramjet system begins operation at Mach 4.0 to 4.5 to facilitate a smooth transition between low- and highspeed operation. The vehicle contains sufficient hydrogen to reach and engage the target, turn, and begin the unpowered descent. Sufficient hydrocarbon fuel is retained on board to allow a 10 minute loiter waiting for the tanker.

An alternate mission scenario investigated was a one-way trip with no direct return to CONUS and no refueling. After engaging the target, the vehicle would continue on to some remote U.S. base. A 10 minute fuel reserve is retained for approach and landing. This scenario may be desirable from a logistical standpoint in order to eliminate the need for refueling. However, it may require the installation of a cryogenic fuel capability at the remote base.

For each of these mission scenarios, the effect of fuel selection (dual fuel vs. hydrogen) was examined. The all-hydrogen mission performance was calculated two ways. The first approach simply replaced the volume of JP fuel with an equivalent volume of slush hydrogen. Because of the density difference, this led to a much lighter vehicle. Another option was investigated which eliminated the JP fuel and re-sized the all-hydrogen vehicle to the same TOGW as the dual-fuel version.
Figure 11 summarizes the ranges associated with these alternate vehicles and missions, scaled relative to the reference vehicle on the baseline return mission. For the return mission the dual-fuel vehicle shows a distinct advantage in mission radius based on its ability to inflight refuel. On the other hand, for the oneway mission, the all-hydrogen vehicle is superior, either with the same volume, or resized to have the same TOGW. This results from the fact that the specific impulse $\left(\mathrm{I}_{\mathrm{sp}}\right)$ for the lowspeed propulsion system is an much as 2.5 times higher for hydrogen than for hydrocarbon fuel. With this added range comes the operational complexity of having to base a cryogenic fuel capability at a non-CONUS site.

\section{Summary}

A Mach 10 cruise vehicle provides a quick response, global reach capability with high survivability. For operations from CONUS, mission radii on the order of $8,000 \mathrm{nmi}$ are sufficient. For missions which return to CONUS, a dual-fueled vehicle is superior, due to its capability to in-flight refuel. However, for one-way mission, an all-hydrogen vehicle is preferable because of its higher specific impulse.

\section{Acknowledgements}

John Martin and John McGuire of LockheedMartin.

\section{References}

1. Hunt, J.L.: Airbreathing/Rocket SingleStage-to-Orbit Design Matrix. AIAA Paper 95-6011, Apr. 1995.

2. Pegg, R. J.; Hunt, J.L.; Petley, D.H. and all: Design of a Hypersonic Waverider-Derived Airplane. ALAA Paper 93-0401, Jan. 1993.

3. Bogar, T.J.; Eiswirth, E.A.; Couch, L.M.; Hunt, J.L.; and McClinton, C.R.: Conceptual Design of a Mach 10, Global Reach Reconnaissance Aircraft. AIAA 96-2894, Jul. 1996. 


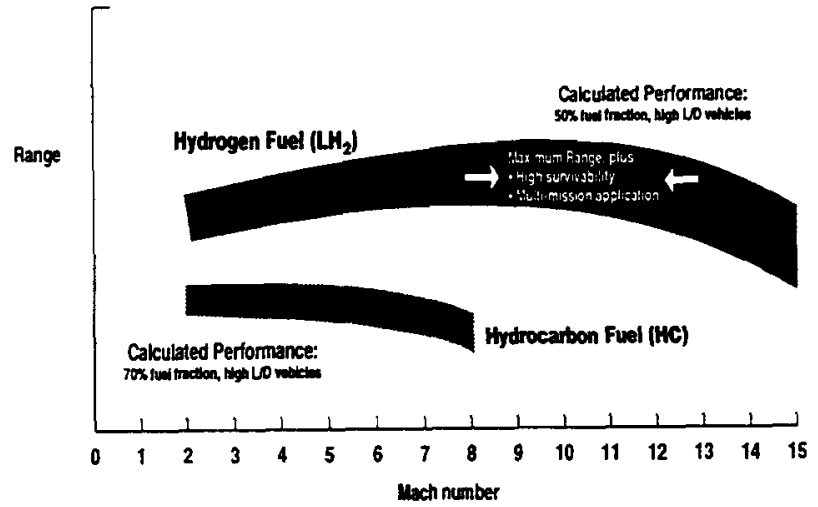

Figure 1. Range potential for hypersonic airplanes (fixed payload).
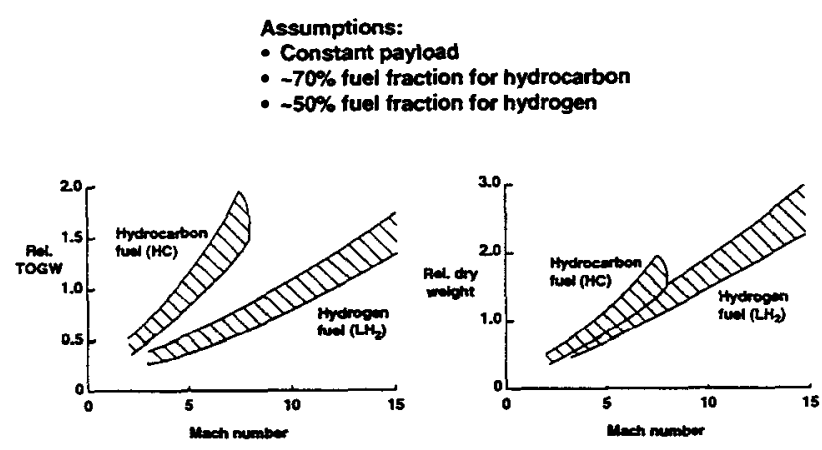

Figure 2. Weight potential for hypersonic airplanes (fixed payload).

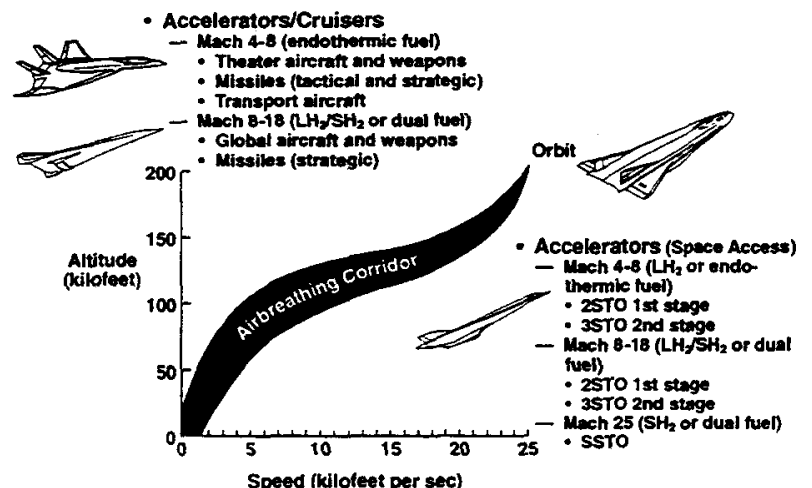

Figure 3. The hypersonic airbreathing matrix... vehicles, applications, and flight envelope.

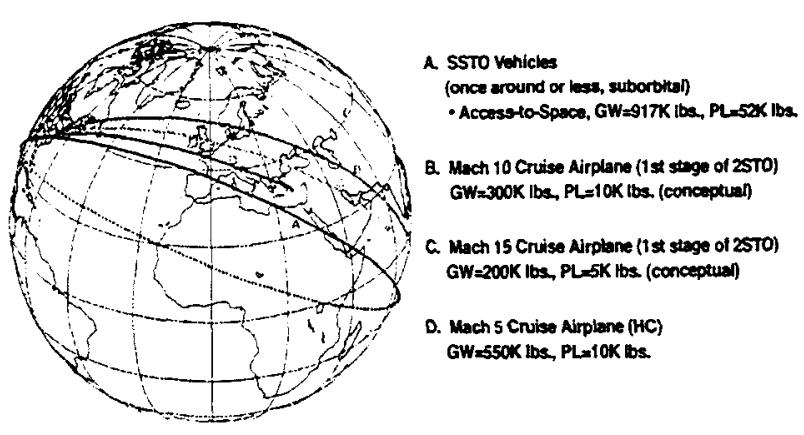

Figure 4. Conceptual conus-based global delivery potential for airbreathers (endoatmospheric operations, ground-to-ground).

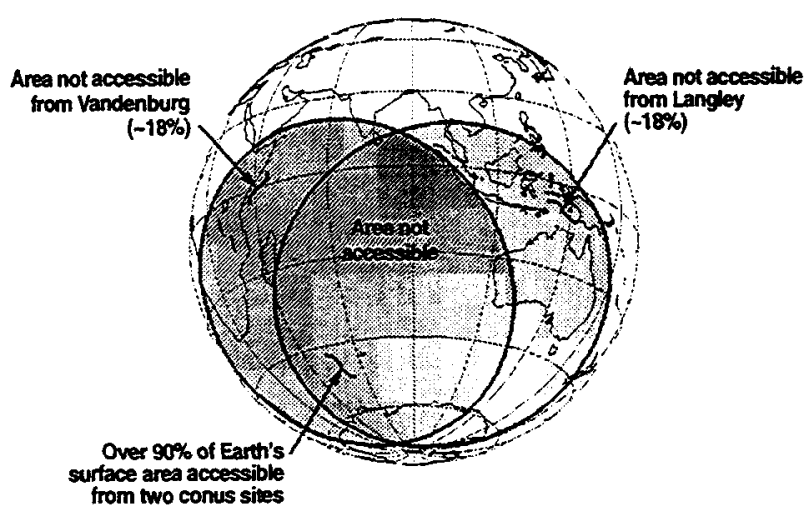

Figure 5. Global reach of aircraft with $10 \mathrm{~K}$ nm range from Langley and Vandenberg airbases (landing sites and/or return not considered).

For global access/space access in a logistically manageable, synergistic system with in-air refueling capability, consider:

- Mach 10 cruise/stage*

- Acetr low-speed system

- Dual fuel...endothermic/liquid hydrogen This staging capability would require a rocket in the tail end of
the aircraft to perform a pull-up maneuver to reach low dynamic
pressures for staging.

Figure 6. Overall perspective-space access and endoatmospheric 


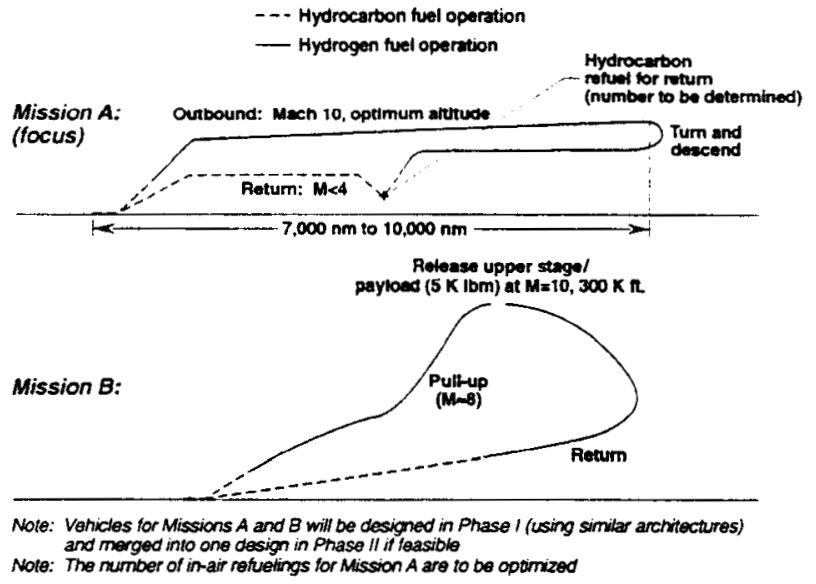

Figure 7. Mission scenarios.

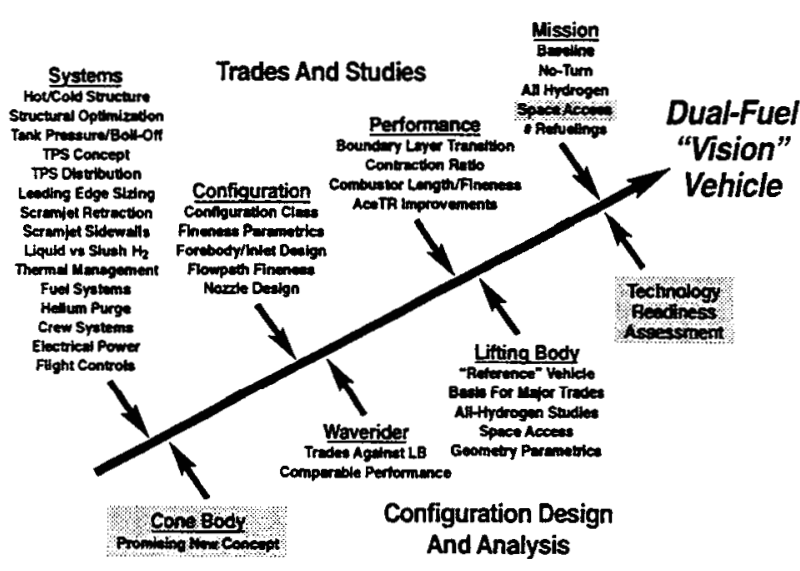

Figure 8. Phase 1 effort aimed at developing dual-fuel vision.

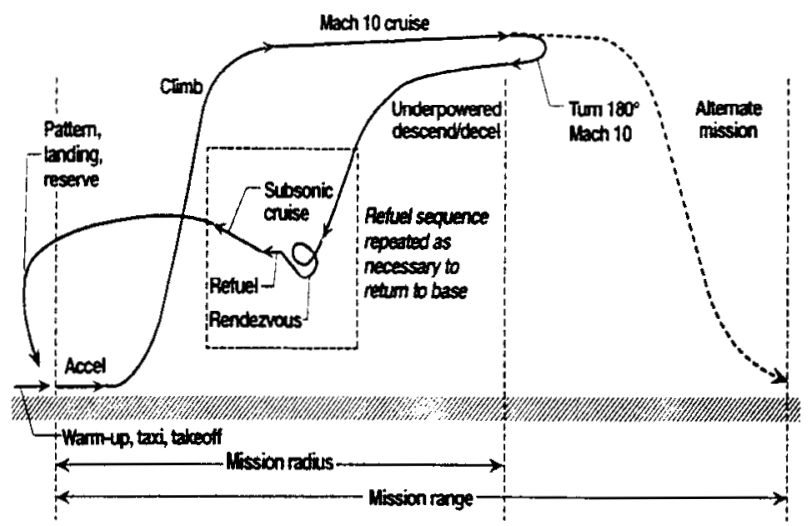

Figure 10. Candidate hypersonic cruise mission scenarios.

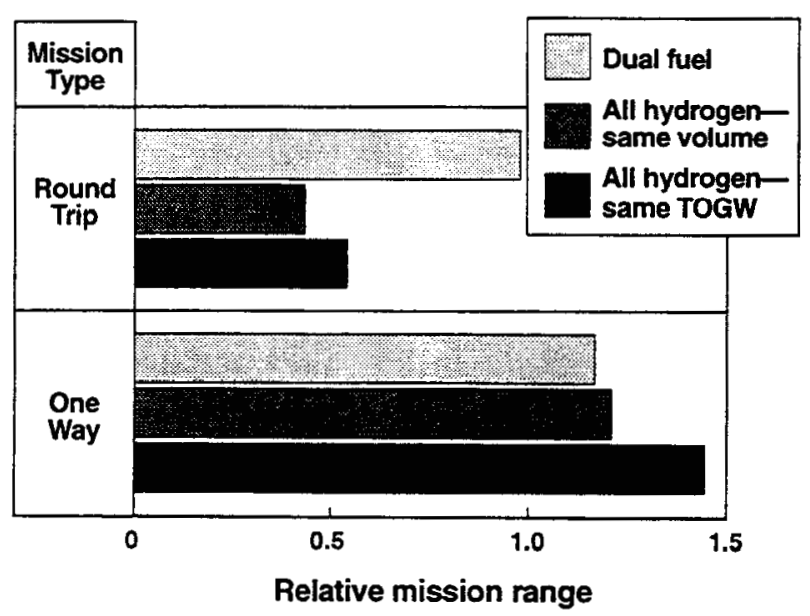

Figure 11. Alternate mission scenario summary.

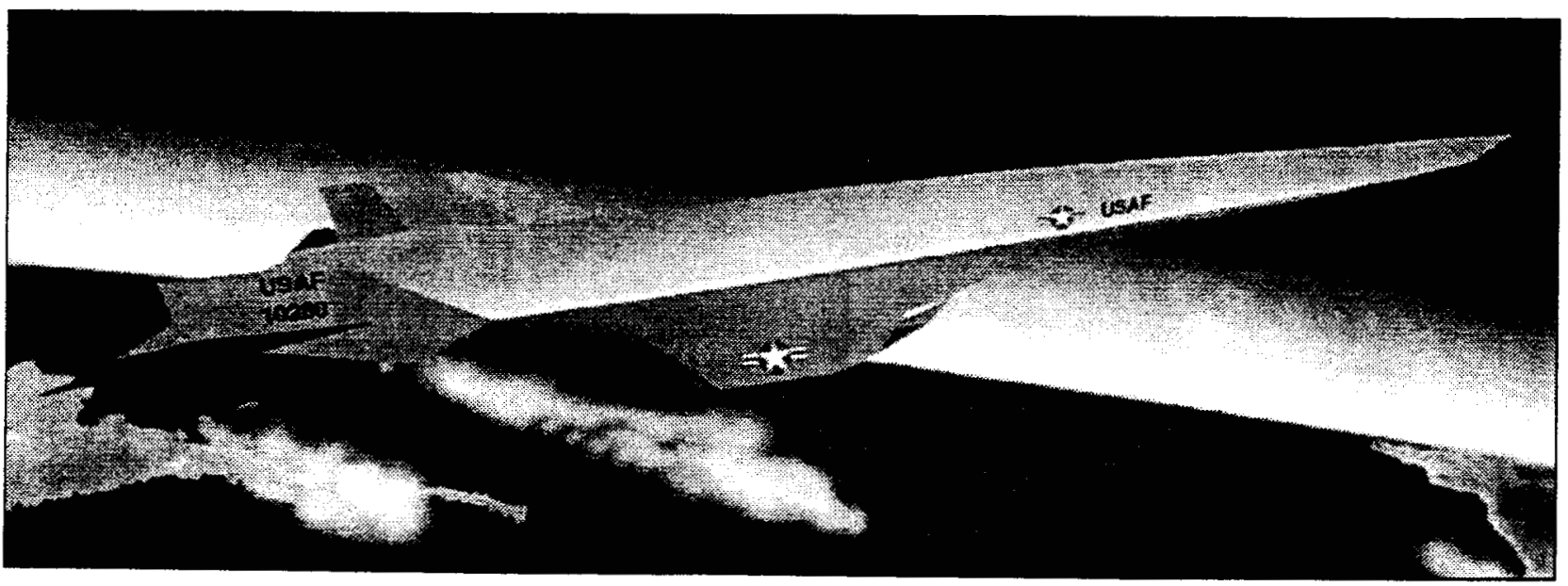

Figure 9. Dual-fuel airbreathing hypersonic vehicle concept. 